\title{
From cultural to existential diversity: The impossibility of psychotherapy integration within a traditional framework
}

\author{
SANDRA A. RIGAZIO-DIGILIO \\ University of Connecticut, Storrs, School of Family Studies/Marriage and Family Therapy Program
} OSCAR F. GONÇALVES

University of Minho, Portugal

ALLEN E. IVEY

University of Massachusetts, Amherst, School of Education/School and Counseling Psychology

\begin{abstract}
The authors build upon Castonguay and Goldfried's anaiysis regarding issues and directions central to advancing psychotherapy integration. They elaborate on two issues addressed only minimally in Castonguay and Goldfried's article. The first involves moving beyond traditional psychotherapy territory to include cultural, self-in-relationship, and interdisciplinary domains. The second concerns using more holistic and synergistic processes to coconstruct integrative theories and approaches. Finally, the authors offer some insights into what they believe should be the goals of the integrative movement and into additional issues they think should be addressed to attain these goals. Psychotherapy has become so complex and changing that we need a new view-one that recognizes the impossibility of any final or superior integrative theory and the need for constant change and evolution in theory and practice.
\end{abstract}

Key Words: Constructivism, Interdisciplinary collaboration, Integration, Integrative psychotherapy, Multiculturalism and psychotherapy

And I have written three books on the soul, Proving absurd all written hitherto, And putting us to ignorance again.

Ib. $l .57$

Robert Browning

The diversity of psychotherapy theory virtually demands that we manage it in some comprehensible fashion. Data and clinical evidence clearly show that more than one approach "works." During the past decade, we have seen the emergence of theories and practices that seek to integrate psychotherapy in a consistent fashion. We have moved from determining which theory is best to discovering how we can integrate and organize what we know.

Send correspondence and reprint requests to: Sandra A. Rigazio-DiGilio, $\mathrm{PhD}$, University of Connecticut, School of Family Studies/Marriage and Family Therapy Program, 348 Mansfield Road, Box U-58, Room 106, Storrs, CT 06269.
This article seeks to explore the complexity of theoretical integration and to question the possibility of whether we can indeed provide a true integration. We suggest that efforts to this point have failed to take important variables into account, particularly as these relate to cultural and contextual issues. Psychotherapy integration is a movement whose time has come, but this movement needs to examine itself, its goals, and its methods. The intent here is to encourage dialogue and the development of multiple narratives regarding theoretical and practical integration.

Many authors, themselves from diverse perspectives, have identified key factors that have led to the trend toward theoretical integration (cf. Beutler, 1983; Ivey \& Gonçalves, 1989; Mahoney, Norcross, Prochaska, \& Missar, 1989; Arkowitz, 1992; Goldfried \& Newman, 1992; Castonguay \& Goldfried, 1994; Rigazio-DiGilio, 1994). The integrative movement seeks to build more comprehensive theories of human and systemic functioning expand, perspectives regarding therapeutic change, and offer more cohesive frame- 
works to guide the use of broader repertoires of psychotherapy interventions (cf. Garfield \& Kurtz, 1977; Gurman, 1981; Dryden, 1986; Beutler, 1986; Norcross \& Prochaska, 1988; Van Hesteren \& Ivey, 1990; Ivey \& Rigazio-Digilio, 1991; Goldfried \& Castonguay, 1992; Goldfried, Castonguay, \& Safran, 1992; Castonguay \& Goldfried, 1994). At the same time, it can be argued that much of the integrative discourse is more of the same-specifically, that the integrative movement has remained embedded within a positivist epistemology and has given insufficient attention to alternative constructivist, developmental, and ecological frames of reference.

Castonguay and Goldfried (1994) ably point out that the integrative movement has provided opportunities for increased dialogue among traditional schools of psychotherapy and has extended the frames of reference theoreticians, clinicians, and researchers can draw upon to advance their work (cf. Goldfried, 1982, 1987; Arkowitz, 1989; Beutler, 1989; Grencavage \& Norcross, 1990; Mahalik, 1990; Lambert, 1992; Castonguay, 1993; Stricker \& Gold, 1993). Nonetheless, we note two primary constraints in the directions suggested by Castonguay and Goldfried (1994) - one has to do with the territory of investigation while the other has to do with the process of investigation.

Castonguay and Goldfried (1994) suggest that the territory explored by psychotherapy integrationists primarily consists of three traditional orientations: humanisticexperiential, psychodynamic, and behavioral. We contend that noteworthy omissions include the epistemological, theoretical, clinical, and empirical foundations inherent in other mental health disciplines such as psychiatry, particularly object relations and attachment theory (cf. Bowlby, 1969, 1973; Frances, Clarkin, \& Perry, 1984; Kohut, 1984; Masterson, 1981), Winnicott, 1980, social work's emphasis on contextualism (cf. Levy, 1973; Hartman \& Laird, 1983), the systemic/contextual view of marriage and family counseling and therapy (cf. Patterson, 1971; Bowen, 1977; Minuchin \& Fishman, 1981; Watzlawick, 1984; Dinkmeyer \& Dinkmeyer, 1991; Sperry \& Carlson, 1991; Rigazio-DiGilio \& Ivey, 1993; Amatae \& Sherrard, 1994) and counseling's movement toward social constructivism (cf. Ivey, 1986, 1991; Ginter, 1988; Heppner \& Claiborn, 1989; Herr, 1991). Additionally, traditional integrationists tend to ignore important discoveries in ethnic and cultural writings (cf. Pedersen, Draguns, Lonner \& Trimble, 1989; Meyers, Wohlford, Guzman, \& Echemendia, 1991; Vargas \& KossChioino, 1992; Trickett, Watts, \& Birman, 1994). Other omissions include discoveries in biology, anthropology, sociology, and physics.

Due to these above omissions, the impression one is left with is that psychotherapy integrationists do not often extend themselves beyond the border of their professional competence. Rather, integrationists, as generally defined, are less proficient at challenging or transforming their predominant frameworks by examining other accessible alter- native vantage points. Further, and more importantly, by remaining within the confines of traditional North American and European territory, integrationists are less able to challenge the cultural constraints of their theories, approaches, and empirical investigations. Admittedly, the task of psychotherapy integration, when viewed from a larger perspective, begins to appear impossible. But, perhaps a beginning approach to the important and essential task of integration is actually becoming aware of the impossibility of what we seek-a holy grail that is well worth searching for, but may always elude us.

The process used by psychotherapy integrationists also constrains their ability to coconstruct truly alternative models of human functioning and therapeutic change. The prevailing process, identified by Castonguay and Goldfried (1994), has been to develop synthetic theories of psychotherapy and to then clinically and empirically verify the usefulness of these models. This top-down approach to theory and therapy construction relegates clinical and empirical explorations to a lesser position than theoretical conceptualizing (cf. Whitaker, 1976; Vandenberg, 1991; Epstein, 1994).

If alternative perspectives, approaches, and investigations are to emerge beyond the boundaries of an existing conceptual knowledge base, then there must be processes of inquiry that directly link theory, research, and practice in ways that allow each to equally inform the others (cf. Howard, 1984; Rice \& Greenberg, 1984; Piercy \& Sprenkle, 1985; Anderson, Goolishian, \& Windermand, 1986; Gergen, 1994). As stated by Atkinson, Heath, and Chenail (1991), "the legitimization of knowledge requires the judgement of an entire community of observers and is most appropriately a democratic process in which all stake holders have equal input" (p. 162).

It is our assertion that if the integrative movement in psychotherapy ignores these key territorial and process constraints, the end point will be insulated, albeit newly packaged versions of psychotherapy that are not accessible to challenge or to movement beyond the borders of narrow traditions. In this article, we build upon the analysis provided by Castonguay and Goldfried (Psychotherapy integration: An idea whose time has come, 1994) regarding the issues and directions central to advancing psychotherapy integration. To accomplish this, we elaborate on two contextual issues that are addressed only minimally or omitted in their discussion. The first involves moving beyond the traditional psychotherapy territory to include cultural (e.g., Pedersen, 1994), self-in-relationship, (e.g., Hoffman, 1992) and interdisciplinary (e.g., Rigazio-DiGilio, Gonçalves, \& Ivey, 1994) contexts. The second concerns using more holistic and synergistic processes to coconstruct integrative theories and approaches. Finally, we offer some insights into what we believe should be the goals of the integrative movement and into additional issues we think should be addressed to attain these goals. 
Emphasizing the need for diversity and multiple perspective-taking, our purpose is to add another voice to the discourse concerning psychotherapy integration. We hope the points made in our article will help to foster extended dialogue as the field continues its struggles to coconstruct comprehensive, effective, and continually changing integrative frameworks.

\section{The Territory as It Has Been Defined May be Oppressive}

The basic assumptions that the three orientations reflective of our well-established traditions (humanistic-experiential, behavioral, and psychodynamic) are "probably here to stay" (p. 166) and that there will continue to be a "movement toward rapprochement and integration [among these established models]" (p. 168) indicates the territorial bias evident in Castonguay and Goldfried's (1994) analysis of integrative psychotherapy. The omission of possibilities that alternative assumptions, perspectives, and approaches may be available within other disciplines or socio-cultural contexts, or that optional metamodels could emerge from open dialogues that include these other contexts speaks to a constrained view of what constitutes credible territory. Castonguay and Goldfried's perspective is made clear throughout their article and is exemplified in their position that " . . attempts at raproachment [among the three central orientations] may well provide fruitful avenues of improvement for each major orientation without repudiating the principles and philosophical bases of their main interventions" (p. 166) (italics added).

By implying that the three orientations will maintain their centrality, and that the philosophical assumptions undergirding each orientation will not be altered, obscures the potential influence of a multitude of forces. For example, by neglecting the impact of epistemological (e.g., Polkinghorne, 1992), socio-political (e.g., Friere, 1990), multicultural (e.g., Falicov, 1988), interdisciplinary (e.g., Pinsof, 1994) gender-sensitive (e.g., Freud, 1994), multidimensional self (e.g., Gergen, 1992), and ecosystemic (e.g., Auerswald, 1983) factors, the evolution of integrative psychotherapy models cannot hope to address the needs of a diverse and rapidly changing world.

Let us turn now to examining a possible additional frame of reference: one that focuses on an ever-changing multidimensional, multiperspective world.

\section{The Expanded Options Available in Multicultural and Multiphrenic Territories}

The concept of integrating traditional psychotherapy theories has been challenged by two central socio-cultural trends. These are the multiphrenic and multicultural trends that have surfaced due, in part, to the transformations we are facing as an outgrowth of a postmodern world.
Linking multiculturalism and psychology. As stated, traditional psychotherapy theories emerged within a North American and European culture, and, as such, manifest customs, mores, values, philosophies and language reflective of this experience (Sue \& Sue, 1990; Ponterotto \& Casas, 1991; Rigazio-DiGilio \& Ivey, 1995). For this reason, many have attacked traditional theories as a means of social control (Szasz, 1961; Halleck, 1971; Sue, 1981; Katz, 1985) and as a possible form of cultural oppression (e.g., Casas, Ponterotto, \& Gutierrez, 1986; Cheatham \& Stewart, 1990; Sue, 1978; White \& Parham, 1990).

These criticisms are most evident when mental health professionals naively assume that the values and dispositions inherent in psychotherapy theories are universally held and seek to impose these beliefs on clients ${ }^{1}$ who may differ in terms of racial/ethnic, gender, socio-economic, and other characteristics (Sue, Ivey, \& Pedersen, 1996). As a way of illustration, culture-bound values associated with individual responsibility, action-oriented solutions, and client selfdisclosure are in direct conflict with clients who value collective responsibility, emotional/spiritual solutions, and nonverbal communication. Other illustrations are provided by authors speaking to the issue of multiculturalism in psychotherapy.

Unlike the Western philosophic system, the African tradition has no heavy emphasis on the individual; the individual's being is authenticated only in terms of others'. Nobles (1972) writes that there is a sense of corporate responsibility and collective destiny in the traditional African self-concept: "I am because we are; and because we are, therefore, I am." (Cheatham, 1990, p. 375)

American Indian communities are distinguished by many ties among tribal members and strong group cohesion, particularly in times of crisis. Indian people have concerns about psychological concepts like "mental health," "personality," and "self" because of the absence of naturalistic or holistic concepts in the design and implementation of therapeutic processes. ... (They) often express concern about how conventional Western psychology superimposes biases onto American Indian problems and shapes the behavior of the client in a direction that conflicts with the Indian cultural life-style orientations and preferences. ... Many American Indians recognize the need for professional assistance only when informal community-based networks are unavailable. (LaFromboise, 1988, p. 392)

Feminist analysis is political, in that it is essentially an identification and assessment of power relations located centrally in gender. Feminist analysis contains an impor-

\footnotetext{
${ }^{1}$ In this article, client refers to individuals, partners, families, or wider social networks involved in the therapeutic encounter.
} 
tant focus on the social, economic, cultural, and institutional contexts that form and define individuals' lives, values, cognitions, emotions, motiviations, and work and kinship patterns. ... (This book) raise(s) serious questions about whether the traditional personality theories can simply be redesigned. . . . The challenge inherent in these (feminist) critiques require fundamental change in contextual and structural metaphysics, as well as epistemological expansion. (Brown \& Ballou, 1992, p. 6)

Realizing that traditional psychotherapy theories are limited in terms of multicultural applicability is an essential first step toward coconstructing integrative theories that will meet the existential needs of diverse clientele. In his proposal regarding culturally oriented psychology, Bruner (1990) reminds us that "human beings do not terminate at their own skins, they are expressions of a culture" (p. 12). The recognition of the central role that culture plays in the construction and transformation of meaning is becoming more central to psychotherapy theory, practice, and research (cf. D’Andrea \& Daniels, 1991; Rigazio-DiGilio \& Ivey, 1995; Sue et al., in press; Pedersen, 1994). We believe that viable theories of psychotherapy integration must account for the multicultural realities inherent in our postmodern world, and that this essential component of the integrative movement has been omitted in the Castonguay and Goldfried analysis.

Linking multiphrenia and psychology. The intrapsychic conceptions undergirding traditional psychotherapy perspectives also have been challenged by influences brought about by the postmodern world. Traditionally based, intrapsychic psychotherapy models assume that the self is constituted by inner processes and that the nature and general rules of these processes can be identified. As a consequence, unified, intrapsychic psychotherapy theories were devised. Psychotherapists became, what Cushman (1992) refers to as Doctors of the Interior.

In contrast to these traditional views, postmodern perspectives, such as the one exemplified by Gergen (1991), characterize the actual self as a self in multiphrenia. That is, the spreading of the individual into multiple investments within and across life history.

Increasingly we emerge as the possessors of many voices. Each self contains a multiplicity of others, singing different melodies, different verses, and with different rhythms. Nor do these many voices necessarily harmonize. At times they join together, at times they fail to listen to one another, and at times they create jarring discord. (p. 83)

This perspective is echoed by Ogbonnaya (1994), who states " . . from an African worldview, the human person must be seen as a community in and of itself, including a plurality of selves" (p. 75). It is further exemplified by many in the marriage and family therapy field (cf. Anderson \& Goolishan, 1988; Hoffman, 1990; White \& Epstein, 1990; de Shazer, 1991; Parry, 1991). Their writings encourage therapists to assume a narrative or conversational model that emphasizes the ways individuals construct personal meaning and that allows the multiplicity of individual and collective voices to be heard during the therapeutic encounter.

This multiphrenic perspective represents a natural adaptive response to a society where change and diversity are central themes. Given recent advancements in the technologies of communication and transportation, we experience variety and diversity each day of our lives. Additionally, in this day and age, people often survive the utility of their learned skills or the disappearance of their own professions. Changes in family structures, political affiliations, economic conditions, citizenship, and religion also are becoming more common.

As such, people not only experience variety and diversity between self and other, but also within self. The self is a self in project - a self projected in a process of constant movement (Gonçalves, 1994; in press). The idea of an integrated self is increasingly replaced by the notion of a differentiated self, or a self that can actualize multiple potentialities within different contexts and over time (cf. Minuchin, 1974; Anderson \& Sabatelli, 1990; Rigazio-DiGilio, \& Ivey, 1991, 1993; Breunlin, Schwartz, \& Kune-Karrer, 1992).

This notion of the differentiated self is not fully captured in our traditional psychotherapy models and should be accounted for in the coconstruction of integrative perspectives. This is a case in point where available theories, approaches, and research within other disciplines could help to stretch the borders of traditional psychotherapy. We have been caught so long in the traditional individualistic epistemology that it will take a major effort to reconstruct and reconstrue this newly evolving approach. Developing and accessing such alternative perspectives would provide a counterbalance to Castonguay and Goldfried's (1994) recommendation that we first initiate "comparative analyses of pure form [traditional psychotherapy] therapies [prior to] the study of integrative or eclectic approaches" (p. 168). What does seem clear is that we no longer can continue with "more of the same."

Bridging multiculturalism and multiphrenia. The movement within ourselves is also a reflex of a movement between ourselves. A person only exists in relationship (cf. Minuchin, 1974; Bowen, 1977; Auerswald, 1983) and this relationship takes place in diverse multicultural scenarios (cf. Falicov, 1988; McGoldrick, Pearce, \& Giordano, 1989; Rigazio-DiGilio \& Ivey, 1995). A multiplicity of cultures come together into a globalization of societies. These cultures represent different life-styles. There is a confluence of existential options that coexist in the microcosms of work, educational, home, and social environments. This multitude of voices is progressively recognized as possible and necessary for an enrichment and complexification of the ex- 
perience. To accomplish this, we must accept integrative psychotherapy itself as a multiphrenic and multicultural proposal as opposed to the more narrow conception of integrating traditional psychotherapy models espoused by Castonguay and Goldfried (1994).

In an analysis of the role played by collective minority movements in the transformation of psychology, Sampson (1993) warns that:

In the long run, psychology's legitimacy resides in the hands of the people. These people have become both more diverse and more restless. Their differences are showing and will not be silenced by appeals to the ideas that continue to speak in the voice of the dominators. Either psychology will listen and change, or it will lose its thrust as an important contributor to the tasks of our time. (p. 1228)

Two issues undergirding mainstream scientific psychology are being shaken by the multiple voices of contemporary society. The first, as discussed before, is the idea of the psychologist as a Doctor of the Interior. The essentialist position that persons are defined by inner structural identity is being progressively substituted by a psychology focused on what Bruner (1992) refers to as acts of meaning. The second issue is that the sacred cow of an individual self (Hoffman, 1992) is being replaced by a concept of self-inrelationship. That is, people are defined by the interactional nature of their thoughts, experiences, and actions (cf. Bagarozzi \& Anderson, 1989; Guidano \& Liotti, 1983; Ivey, 1986; Rigazio-DiGilio, 1994). Ivey, Gonçalves, and Ivey (1989) translate this notion into the therapeutic arena by noting that issues promoting treatment are, in fact, coconstructed in a constant person-environment dialectic. This coconstruction evolves as a natural and logical consequence of the reciprocal interactions that occur between individuals and the cultural and social environments they have been involved with over time. Drawing from feminist theory (cf. Brown \& Ballou, 1992), coconstructive psychotherapy involves working with rather than on the client. The therapist becomes colearner, and coevolves with the client through the therapeutic process. Theory building may benefit from a parallel process: how can we learn with our clients, with those who conduct therapy, with empirical investigators, and with those who take vastly different conceptions of the human experience.

Psychotherapists consequently need to become different types of professionals. Rather than professionals of internal integration, they are required to assume the role of Doctors of Interpersonal Diversity. This is the point where multicultural and multiphrenic societies come into crossroads with a cultural conception of psychology and psychotherapy (Van Hesteren \& Ivey, 1990a, 1990b; Ivey \& RigazioDiGilio, 1991; Nwachuku \& Ivey, 1991; Ogbonnaya, 1994).
Psychology should then be focused on an interactional, moving, multivoiced, individual-in-relationships, framework. This represents a new departure for psychotherapy, challenging the traditional expert and objectivist model, in favor of a model where, as Lax (1992) describes:

Clients unveil the story of their lives in conjunction with a specific reader/therapist, therefore the therapist is always a co-author of the story that is unfolding, with the client(s) as the other co-author(s). The resulting text is neither the client's nor the therapist's story, but a coconstruction of the two. (p. 73)

It is doubtful that such alternative coconstructive models of psychotherapy will be foreclosed by integrative theories that emerge from the traditional psychotherapy models identified by Castonguay and Goldfried (1994). Quite the contrary, we believe that we all need to become increasingly aware that our roots are not as deep or as solid as we once thought. Additionally, we need to face the prospect that metamodels that encapsulate and transcend the boundaries of traditional psychotherapy theories, tap the resources of allied disciplines, and incorporate the realities of our postmodern world will be needed to understand and respond to the coconstructive, culturally diverse process now occurring.

\section{Expanding into Interdisciplinary Territories}

Integrating theoretically and therapeutically useful perspectives from individual, systemic, and wider network paradigms has become a central issue in most mental health disciplines. There appear to be four main perspectives regarding this issue. On the one hand, some contend that metamodels, based on overarching alternative paradigms, can be used to synthesize perspectives and methods across disciplines (e.g., Breunlin et al., 1992; Pinsof, 1994; Rigazio-DiGilio et al., 1994). Others contend that linkages can be made among the assumptions undergirding existing paradigms, providing a course for integration that goes beyond the borders of any one discipline (e.g., Sugarman, 1986; Brighton-Cleghorn, 1987; Feixas, 1990). Another perspective suggests that a particular predominant paradigm within one discipline can serve as the umbrella that subsumes other perspectives or disciplines (e.g., Held, 1986; Wachtel \& Wachtel, 1986; Terry, 1994). Still others only explore the potential linkages within their primary discipline (e.g., Case \& Robinson, 1990; Lazarus, 1986).

By omitting the concept of interdisciplinary bridging altogether, it is our contention that Castonguay and Goldfried (1994) fall within this last perspective. We, on the other hand, believe that linkages can be realized among disciplines to better treat the multicultural and multiphrenic aspects of our clients. These linkages can be made by recognizing alternative overarching paradigmatic lenses that link seemingly divergent perspectives or by exploring 
interdisciplinary linkages among the various assumptions undergirding different perspectives.

In support of this view, ecosystemic advocates (Auerswald, 1983; Attneave, 1969; Minuchin, 1974; Anderson et al., 1986; Imber-Black, 1988; Hershenson, Power, Seligman, 1989; Wiekel \& Palmo, 1989; Herr, 1991; RigazioDiGilio, 1994) suggest that key elements of a client's wider ecology be addressed in our theories of human, systemic, and therapeutic development, as well as in our models of practice and our research methodologies. This ecological domain includes the identified client, the immediate and extended family, friends, coworkers, employers, representatives of social and community agencies, and other aspects of the wider historical, socio-cultural, and political context.

Theoretical perspectives, therapeutic approaches, and investigatory techniques stemming from these ecosystemic assumptions represent various ways to integrate theories of individual, family, and social network development and theories of therapeutic change. Each model represents an additional, wider lens in a continued search for deeper understanding of human and systemic interdependence. Furthermore, the authors of such models imply three important positions: (1) that they represent part of a movement to help us better tailor perspectives and approaches to the unique needs of a multicultural and multiphrenic society; (2) that their models are presented in a way that opens foundational assumptions to pragmatic and empirical scrutiny and dialogue; and (3) that their models are temporary versions of integrative processes that will continually be enhanced, modified, and transformed.

Many of these authors have coconstructed their models in constant dialogue with theoreticians, clinicians, and researchers. They open their models to clinical and empirical feedback and often revise and transform their models in light of this feedback. This leads us to the next topic of discussion in our response to Castonguay and Goldfried's (1994) article: that is, the processes inherent in integrative theory and therapy coconstruction.

\section{Process: Interrelationship between \\ Theory, Practice, and Research}

Let us begin by exposing a major dilemma faced by most psychology interns in their first ventures into the clinical arena. Ideally, they go to their practice well equipped with an armor of one or a few scientific theories and therapeutic approaches. However, when facing the diversity of the clinical reality, they suddenly realize that the theories and approaches they learned seldom match what they encounter. As good students of the top-down epistemology they return to their theories and techniques rather then learning from their practice, accompanied with a strange guilt feeling that they may have missed something. What they fail to realize is that the source of a new knowledge may well be personified by the client they are facing. In doing so, an opportunity is lost for the epistemological obstacle of the clinician to turn into an epistemological encounter with the client.

There are, however, increasing signs that practitioners are uncomfortable with the traditional scientist-practitioner model (e.g., Tyler \& Clark, 1987). Many clinicians now question if practical knowledge is secondary, or if it is an equal and alternative source of knowledge. This is what Polkinghorne (1992) refers to as a new epistemology of practice: a neo-pragmatic attitude that recognizes practical knowledge as a necessary foundation for the development of psychotherapy. Rather than transforming psychotherapists into applied professionals of theory and research, the professional practice of the therapist can be the ground of theory and research itself. In this regard, clinical practice constitutes a knowledge that not only results from a rational and conceptual framework, but also recognizes existence and experience as central elements in human knowing (Epstein, 1994; Vandenberg, 1991). With such approaches we move to the high context knowing which is practice, whereas abstract theorizing and research is often low context. The parallel with high context cultures such as Japan and the low context United States culture should be apparent. Both experience and context are vital; yet we should not forget that the low context, abstract mode of traditional theory has value as well.

Regarding the research domain, data from several metaanalyses on the effectiveness of psychotherapy have repeatedly demonstrated that "not only is there clear evidence for the effectiveness of therapy relative to untreated patients, but psychotherapy patients show gains that surpass those resulting from pseudotherapies and placebo controls" (Lambert \& Bergin, 1994, p. 181). However, the differential outcomes between different types of psychotherapies have not found significant support. Therefore, the Dodo's verdict that "all won and all deserve their prizes" suggested by Stiles, Shapiro, and Elliot (1986) still holds.

The absence of differential effectiveness has moved many theoreticians, clinicians, and researchers to an openmindedness, rejecting adherence to a given school in favor of the diversity of therapeutic methodologies. This corresponds to what Lambert and Bergin (1994) call a healthy response to empirical evidence. This response may lead to a more idiosyncratic exploration of the role of client, therapist, and contextual variables (cf. Beutler, Machado, \& Neufeldt, 1994). Such research consistently supports the idea that patient and therapist variables, and the contextual nature of their relationship represent major determinants of therapeutic success (cf. Lambert \& Bergin, 1992). The wide acknowledgement of the importance of idiosyncratic variables has moved researchers to look for alternatives to what Omer and Dar (1992) refer to as theory-driven research. Again, it seems that the time has come to return to pragmatics in the direction of the new epistemology of practice. It is our contention that clinical experience and empirical investigation should inform theory construction to the same degree that theoretical concepts and techniques inform and 
guide assessment, treatment, and investigation. By assuming parity among theory, practice, and research versus the top-down model espoused by Castonguay and Goldfried, we would no longer be able to assume that definitive general laws are possible. Rather, the wider and more in-depth our own personal knowledge base, the more we could access and challenge our conceptualizations and assumptions based on the immediacy of the therapeutic encounter or on the results of empirical investigation. In this fashion, the alternative sources of knowledge that are accessible in the clinical and empirical domains would assist in the modification, enhancement, or actual transformation of existing theories or integrative metatheories.

Polkinghorne (1991) suggests that "successful therapy has been accomplished by therapists committed to various conceptual networks and practicing a variety of techniques. The psychology of practice accepts the concept of equifinality-the same result can be achieved through a variety of approaches" (p. 161). In other words, if we discipline ourselves to give equal credence to theory, practice, and research in our coconstruction of knowledge, then diversity is not only an inevitable, but above all, a necessary condition for any new science of psychotherapy integration. In this regard, the end result can never be one model of psychotherapy integration but, rather, a variety of conceptual themes and therapeutic approaches that must be learned sufficiently enough to draw upon and question the diverse circumstances inherent in our multicultural and multiphrenic world. Here again, we see the spectra of impossibility raised, but perhaps we also begin to see the value of the impossible dream and the worth of the search.

Several years ago, one of the authors, (A.E.I.) conducted a workshop on Developmental Counseling and Therapy (DCT) in rural Wyoming. The presentation initially reviewed the basic theoretical tenets of DCT and provided empirical evidence supporting each tenet's application to practice-a perfect example of the top-down approach, although originally the model was derived from practice and coconstruction. Two participants later spoke with Ivey regarding the nature of their practice. Their ideas, built upon years of clinical practice, revealed alternative reference points that could promote modifications in DCT. Ivey encouraged both participants to share their ideas more broadly, in publication or presentation format, and was surprised by their perception that their work was not "publication or presentation material."

This set of events is seen, by us, as an outcome of the traditional top-down approach to theory construction. To begin with, traditional psychotherapy, as well as other mental health disciplines, have all played a part in setting an atmosphere that frames scholars as those who have the privilege, power, and capacity to disseminate theoretical frameworks for clinical use and empirical investigation. As way of illustration, how many main line journals are directly related to clinical practice or case studies or have quarterly sections based on clinical practice or case studies? How many articles have you read where a theoretician uses case examples to extend or enhance her or his theory rather than to verify and operationalize its usefulness. And, finally, how many practitioner-oriented masters or doctoral programs offer holistic and synergistic conceptualizations that would ensure that their students recognize the importance of the practitioner in the advancement of any field of study, and then provide avenues and incentives for their students to develop the skills to accomplish this?

Those of us socialized within a traditional top-down approach certainly do contribute to the advancement of our fields, but it is our belief that we have been given more power and authority than we deserve. The end result is often sterile theory and, at times, equally sterile practice as clinicians try to make the perfect theoretical intervention with clients. In our opinion, more direct links between theory, practice, and research-each equally informing the otherscould help to decrease the sterile nature of our theories, and could promote practitioners to bring theories closer to the world of practice.

In a cultural and historical era, which emphasizes the power of the written word, and establishes ownership to those who provide written scholarship, we set up an environment that allows for minimal, and slow-to-evolve dialogues-among select groups-from journal to journal and book to book. The coconstruction of meaning vis-à-vis the oral tradition, or through the provision of equally available outlets for practitioners might serve to provide additional outlets for the coconstruction of knowledge. It is our contention that such formats of expression are needed to begin to encourage a democratic linkage of voices between theoreticians, practitioners, and researchers.

To extend this idea of alternative processes a bit further, we also want to suggest that theory, practice, and research will not provide all the answers or even all of the questions that need to be addressed. The idea that professionals, whether of theoretical, clinical or empirical stripe, will have full command of the field of inquiry is naive. Perhaps, following feminist perspectives and coconstructive models of change, it also is time to involve clients more fully and equally in the process of reconstructing psychotherapy.

\section{Toward an Experiential View of Psychotherapy Integration}

It is our contention that alternative models of integrative psychotherapy that address the two constraints we have identified may provide significant contributions to mental health disciplines as these exist within a multicultural and multiphrenic world. In effect, if we elevated the coconstruction of integrative psychotherapy theories and approaches to the coauthoring process identified by Lax (1992) in his version of the therapeutic encounter, then the synergistic properties inherent in multiple perspective taking could be maximized. Theoreticians, practitioners, and researchers could move from a top-down view of psychotherapy to a cocon- 
structive understanding of human and systemic development and of the therapeutic encounter. Further, these groups could widen their lenses to include knowledge from various fields and from our changing postmodern world.

Over the past decade, the authors of this critique have been involved in the coconstruction of an integrative psychotherapy framework based on a synthesis of traditional perspectives and alternative developmental and coconstructive principles (cf. Ivey, 1986, 1991; Rigazio-DiGilio, 1994; Rigazio-DiGilio et al., 1994). It is our belief that this framework provides one alternative to the coconstruction of integrative models regarding human and systemic functioning and therapeutic change. It offers a flexible account of developmental and coconstructive processes, multiple perspectives regarding domains of intervention, and classification schemes to organize interventions and approaches from various traditional and nontraditional contexts into organized, developmental, and coconstructive versions of treatment. More importantly, through its own coconstructive process and central tenets, this framework provides numerous options for theoretical and therapeutic enhancement and transformation. Using the general principles undergirding the construction of these models, we now review what we consider to be the goals of the integrative psychotherapy movement as well as the issues that should be addressed to attain these goals.

\section{Using Multiphrenic, Multicultural, and Multidisciplinary \\ Territories to Advance Integrative Frameworks}

Any integrative model should provide methods to analyze and understand human and systemic functioning and communication. For example, we believe that language communicates content, reasoning, and culture, and that, as such, it is essential to be aware of the multicultural and multiphrenic nature of the interpersonal communication that occurs during the immediacy of the therapeutic encounter. In this encounter, the specific message (content), as well as the analytic and conceptualization abilities of clients and clinicians are revealed. The historical and cultural influences that shape the expressed content also can be extracted from the coauthoring process that occurs in therapy. It is our belief that most traditional theories posit communication models that can be used to identify specific issues (e.g., resistance, transference, irrational thoughts) but that do not lend themselves to this type of holistic interpretation of human and systemic communication.

Identifying multiphrenic domains. Integrative models can provide frameworks to access and assess individual and collective worldviews. Because worldviews vary across developmental and situational issues, any framework used by theoreticians, practitioners, and researchers must be sensitive to such variations. For example, individuals or systems may use different modes of experiencing, interpreting, and acting for different tasks. Such diversity is indicative of the multiphrenic nature of self and systems. It is when this multiphrenic nature riefies, and individuals and families lose the capacity to access different perspectives across situations, that distress usually occurs. Integrative models need to provide options that safeguard against reducing any client's internal diversity into a static category.

Addressing multicultural domains. No person is an island cut off from the cultural events that have shaped the familial context of existence (Minuchin, 1974; Ivey et al., 1989). Culture is transmitted to individuals through the activities and messages of family and wider socio-cultural contexts. These messages leave their mark on individuals and relationships and are reflected in their worldviews and communication patterns.

Culture is also communicated as particular ways of experiencing, thinking, feeling and acting, and is passed on from one generation to the next (Roberto, 1992). In this sense all current functioning needs to be explained in terms of its socio-historical context. The meaning of particular individual or collective thoughts, feelings, and behaviors needs to be understood in terms of ethnic heritage, developmental history, and contemporary situation. Integrative theories should account for ways individual and collective worldviews are fashioned by these types of historical, familial, and extrafamilial influences. We have found that by attending to worldviews vis-à-vis the narratives provided by clients in the here and now of the interview, clinicians can experience, see, and hear the cultural footprints of the client's socio-cultural and developmental history.

Additionally, to construct integrative models, we must recognize that theoreticians, clinicians, and researchers are not devoid of the historical and contextual roots of culture. Every aspect of their work reflects their culture-such as theory direction, therapeutic approach, and empirical questions. Therefore, we also must be aware of the cultural connotations of our behaviors, words, and work environments.

Connecting multidisciplinary domains. We believe that integrative models must provide metaframeworks for the identification and implementation of interventions and strategies across individual, partner, family, and network treatment approaches. Strategies and interventions should be accessible from a variety of schools and disciplines to address the unique multiphrenic and multicultural needs of each client. Guidelines assisting clinicians to know how far each intervention should be extended and processed during each session, and throughout the therapeutic encounter, should be explicit. In this fashion, the unique cultural, contextual, and personal characteristics of each client can be respected and attended to in treatment planning and during the therapeutic encounter.

Integrative Psychotherapy and the Coconstructive Process As every clinician knows, two clients experiencing the same symptoms will relay very different developmental and contextual histories and will respond differently to the same interventions. The idea that each client is unique has been given lip service in traditional theories but is undermined by 
treatment regimes aimed at particular diagnoses, (e.g., depression, anxiety, and anorexia nervosa), stereotypic classifications (e.g., African American, Scandinavian, Asian American, and Native American), or theoretical conceptualizations (e.g., humanistic-experiential, behavioral, and psychodynamic).

We believe that alternative integrative models should reject the notion of traditional models of diagnostic planning and generalized notions of cultural influences, and substitute a model of treatment planning aimed at the unique needs, issues, orientations, cultures, generations, and contexts of each particular client (see Rigazio-DiGilio et al., 1994).

The idiosyncratic nature of how ethnicity influences personal development can be used as a case in point. There is as much variation within the same ethnic group as there is among different ethnic groups. No one generalization about a person's ethnicity, gender, age, education level, or socioeconomic history holds up for all members of that group. While knowledge of the cultural values of the larger ethnic groups a client belongs to is critical to effective treatment (cf. McGoldrick et al., 1982; Ibrahim, 1985; Sue et al., 1996), how the client reflects or rejects these values is also important (cf. Falicov, 1988). The unique individuality and existential life space of each client must be accounted for in the development of specific treatment plans.

We believe that the role of the clinician should be to monitor, support, and encourage the development and use of unique life options for each client. These options flow from a person's actual life experience. In this sense, clinicians take their lead from each particular client, and not from preexisting, impersonal theory. Interventions and strategies, which may be selected from the various schools of individual, family, or network therapy, are continually evaluated in terms of the reaction of the client.

Thus, at this late point, perhaps it is time to start thinking of bottom-up modes of changing the way we think about the therapeutic process. There are some who would argue that the women's movement, the African-American identity movement, Gay and Lesbian pride, and other consciousnessraising groups have done more for the mental health of those concerned than all our attempts at promoting better psychological health. This list could be expanded to include Alcoholics Anonymous and a multitude of support groups and alternative modes of treatment. Many of the major changes in our practices have come from the public outside our discipline. Certainly, psychology did not invent meditation as a useful stress management technique, although at times it sounds like this too was our discovery. Yet, we must also recognize that traditional research and clinical practice on meditation has expanded the potential of these ideas in our society (cf. Kabat-Zinn, 1990).

Additionally, integrative models should incorporate a dialectic process, wherein all assumptions and principles undergirding the theory are challenged and transformed over time. The coconstructive nature of integrative models should be made evident by continual renewals based upon open dialogues with theorists, clinicians, and researchers. It is this continuous evolution that helps to ensure that integrative models will remain viable conceptual, treatment, and empirical options in our multicultural and multiphrenic society.

\section{Conclusion}

For more than one century, psychotherapists have been facing a complex epistemological dilemma-How can psychotherapy be recognized as a science if the knowledge base stems more from practice than from theory? This dilemma initiated a search for a systematic, universal, and objective knowledge from which our practice should be derived. Gergen and Kaye (1992) identified this process as the elucidation of essences.

Prevalent in the modernist program of science, the elucidation of essences constituted the foundation for the dominant scientist-practitioner model (Raimy, 1950) and generated the traditional territory of the field (i.e., humanisticexperiential, behavioral, and psychodynamic psychotherapy theories). Additionally, defending the process of the clinician as an applied scientist, this model subscribed to a topdown epistemological orientation. In this fashion, practitioners were assigned a secondary role in the construction of knowledge - the role of applied technician (Hoshmand \& Polkinghorne, 1992). The use of this traditional territory and top-down process for the training of clinicians, which advanced about a half-century ago, still inspires policy recommendations (Belar \& Perry, 1992) and remains dominant in more than $90 \%$ of US doctoral training programs (O'Sullivan \& Quevillon, 1992).

In spite of the growing diversity of treatment orientations, there remains interest to develop the foundation of a unitary and integrative theory from which the recommendations for practice can be derived. Again, the idea is that the elucidation of the essences of the traditional models (humanisticexperiential, behavioral, and psychodynamic) identified by Castonguay and Goldfried (1994) can lead toward a new unified science of psychotherapy.

In this article, we have argued that their analysis of the field perpetuates a top-down epistemological process of psychotherapy and is not consistent with the wider territory reflective of a multicultural, multiphrenic, and multidisciplinary worldview.

Holistic integrative frameworks could help move us beyond the confines of existing psychotherapy theories which, focus on slices of the client's life, such as the feeling self (humanistic), the thinking self (cognitive), the behaving self (behavioral), and the interpersonal self (systems). These alternative models could provide integrative tools, which enable clinicians to view their clients as feeling, thinking, behaving, and social beings within a cultural context (multiphrenic selves and self-in-relation). 
The coconstructive nature of reality would also be central in such alternative models of integration. The client and the clinician would be considered coauthors of the story that unfolds in counseling and therapy. This perspective shifts the traditional top-down power structure to a more equal arrangement between client and clinician. This configuration allows for a more inclusive view of treatment that can accommodate an integrative and comprehensive model of theory, practice, and research.

In this article, we also presented the role of language in communicating culture, reasoning, and content and provided our understanding as to why simple top-down epistemologies will not be sufficient in accessing the multiphrenic nature of the self. An integrative model of psychotherapy must not only permit the blending of therapeutic interventions across theories and disciplines, but also must help reveal the unique essence of each client's existential situation.

Finally, if integration is an idea whose time has come, then it will not come from the mainstream psychotherapy models as Castonguay and Goldfried (1994) indicate. Kuhn
(1970) speaks to the change, which spans paradigmatic shifts within a discipline as coming from the edges of the field. Coconstructive, developmental, and integrative models, which synthesize traditional and non-traditional sources of knowledge, represent one such edge within the psychotherapy field. Other marginal areas include cultural psychology, systemic theory, and feminist perspectives. We believe that the models of integrative psychotherapy for the 21 st century will reflect new, more holistic views of human and systemic existence based on a synergistic knowledge constructed through integrative dialogues among traditional and marginalized perspectives and approaches. As such, integrative psychotherapy models will be more than traditional reductionistic models dressed in modern terminology.

We hope the points we make in this article will extend the essential conversation regarding the integrative psychotherapy movement. Further, we hope others will address additional variables that must be considered as we continue this process.

\section{REFERENCES}

Amatae, E., \& Sherrard, P. A. (1994). The ecosystemic view: A choice of lenses. Journal of Mental Health Counseling, 16, 621.

Anderson, H., \& Goolishian, H. A. (1988). Human systems as linguistic systems: Preliminary and evolving ideas about the implications for clinical theory. Family Process, 27, 371-393.

Anderson, H., Goolishian, H. A., \& Winderman, L. (1986). Problem determined systems: Toward transformation in family therapy. Journal of Strategic and Systemic Therapies, 5, 1-14.

Anderson, S. A., \& Sabatelli, R. M. (1990). Differentiating differentiation and individuation: Conceptual and operational challenges. American Journal of Family Therapy, 18, 32-50.

Arkowitz, H. (1989). The role of theory in psychotherapy integration. Journal of Integrative and Eclectic Psychotherapy, 8, 816.

Arkowitz, H. (1992). Integrative theories of therapy. In D. K. Freedheim (Ed.), History of psychotherapy: A century of change (pp. 261-304). Washington, DC: APA.

Atkinson, B., Heath, A., \& Chenail, R. (1991). Qualitative research and the legitimization of knowledge. Journal of Marital and Family Therapy, 17, 175-180.

Attneave, C. (1969). Therapy in tribal settings and urban network interventions. Family Process, 8, 192-210.

Attneave, C. (1976). Social networks as the unit of intervention. In P.J. Guerin (Ed.), Family therapy: Theory and practice (pp. 220-232). New York: Gardner Press.

Auerswald, E. (1983). The Gouveneur Health Service Program: An experiment in ecosystemic community care delivery. Family Systems Medicine, 1, 5-13.

Bagarozzi, D. A., \& Anderson, S. A. (1989). Personal, marital, and family myths: Theoretical formulations and clinical strategies. New York: Norton.

Belar, C. D., \& Perry, N. W. (1992). National conference on the scientist-practitioner education and training for the professional practice of psychology. American Psychologist, 47, 7175.

Beutler, L. E. (1983). Eclectic psychotherapy: A systematic approach. New York: Pergamon Press.

Beutler, L. E. (1986). Systematic eclectic psychotherapy. In J.C. Norcross (Ed.), Handbook of eclectic psychotherapy (pp. 231358). New York: Brunner/Mazel.

Beutler, L. E. (1989). The misplaced role of theory in psychotherapy integration. Journal of Integrative and Eclectic Psychotherapy, 8, 17-22.

Beutler, L. E., Machado, P. P., \& Neufeldt, S. A. (1994). Therapist variables. In A. E. Bergin \& S. L. Garfield (Eds.), Handbook of psychotherapy and behavior change (pp. 229-269). New York: Wiley.

Bowlby, J. (1969). Attachment. New York: Basic Books.

Bowlby, J. (1973). Separation. New York: Basic Books.

Bowen, M. (1977). Family systems theory and society. In J. P. Lorio \& L. McClenathan (Eds.), The Georgetown family symposia: Volume II (1973-1974, pp. 97-121). Washington, DC: Georgetown Family Center.

Breunlin, D. C., Schwartz, R. C., \& Kune-Karrer, B. M. (1992). Metaframeworks. San Francisco: Jossey-Bass.

Brighton-Cleghorn, J. (1987). Formulations of self and family systems. Family Process, 26, 185-201.

Brown, L., \& Ballou, M. (Eds.). (1992). Personality and psychopathology: Feminist reappraisals. New York: Guilford Press.

Bruner, J. (1990). Acts of meaning. Cambridge, MA: Harvard University Press.

Casas, J. M., Ponterotto, J. G., \& Gutierrez, J. M. (1986). An ethical indictment of counseling research and training: The cross cultural perspective. Journal of Counseling and Development, 64, 347-349. 
Case, E. M., \& Robinson, N. S. (1990). Toward integration: The changing world of family therapy. The American Journal of Family Therapy, 18, 153-160.

Castonguay, L. G. (1993). "Common factors" and "nonspecific variables": Clarification of the two concepts and recommendations for research. Journal of Psychotherapy Integration, 3, 267-286.

Castonguay, L. G., \& Goldfried, M. R. (1994). Psychotherapy integration: An idea whose time has come. Applied and Preventive Psychology 3, 159-172.

Cheatham, H. E. (1990). Empowering black families. In H. E. Cheatham, \& J. B. Stewart (Eds.), Black families: Interdisciplinary perspectives (pp. 373-393). New Brunswick, NJ: Transaction.

Cheatham, H. E., \& Stewart, J. B. (Eds.). (1990). Black families: Interdisciplinary perspectives. New Brunswick, NJ: Transaction.

Cushman, P. (1992). Psychotherapy to 1992: A historically situated interpretation. In D. K. Freedheim (Ed.), History of psychotherapy: A century of change (pp. 21-64). Washington, DC: APA.

D'Andrea, M., \& Daniels, J. (1991). Exploring the different levels of multicultural counseling training in counselor education. Journal of Counseling and Development, 70, 78-85.

de Shazer, S. (1991). Putting difference to work. New York: Norton.

Dinkmeyer, D., Jr., \& Dinkmeyer, D., Sr. (1991). Adlerian family therapy. In A. Horne \& J. Passmore (Eds.), Family counseling and therapy (pp. 137-181). Itasca, IL: F.E. Peacock.

Dryden, W. (1986). Eclectic psychotherapy: A critique of leading approaches. In J. C. Norcross (Ed.), Handbook of eclectic psychotherapy (pp. 353-378). New York: Brunner/Mazel.

Epstein, S. (1994). Integration of the cognitive and psychodynamic unconscious. American Psychologists, 49, 709-724.

Falicov, C. J. (1988). Learning to think culturally. In H. A. Liddle, D. S. Breunlin, \& R. C. Schwartz (Eds.), Handbook of family therapy training and supervision (pp. 321-360). New York: Guilford Press.

Feixas, G. (1990). Approaching the individual, approaching the system: A constructivist model for integrating psychotherapy. Journal of Family Psychology, 4, 4-35.

Frances, A., Clarkin, J. F., \& Perry, S. (1984). Differential therapeutics in psychiatry: The art and science of treatment selection. New York: Basic Books.

Freud, S. (1994). The social construction of gender. Journal of Adult Development, 1(1), 37-46.

Friere, P. (1990). Pedagogy of the oppressed. New York: Herder and Herder.

Gergen, K. J. (1992). The saturated self: Dilemmas of identity in contemporary life. New York: Basic Books.

Gergen, K. J. (1994). Toward transformation of social knowledge, (2nd ed.). London: Sage.).

Gergen, K. J., \& Kaye, J. (1992). Beyond narrative in the negotiation of therapeutic meaning. In S. McNamee \& K. J. Gergen (Eds.), Therapy as social construction (pp. 166-185). London: Sage.

Ginter, E. J. (1988). Stagnation in eclecticism: The need to recommit to a journey. Journal of Mental Health Counseling, 10, 3-8.

Goldfried, M. R. (Ed.). (1982). Converging themes in psycho- therapy: Trends in psychodynamic, humanistic, and behavioral practice. New York: Springer.

Goldfried, M. R. (1987). A common language for the psychotherapies: Commentary. Journal of Integrative and Eclectic Psychotherapy, 6, 200-204.

Goldfried, M. R., \& Castonguay, L. G. (1992). The future of psychotherapy integration. Psychotherapy, 29, 4-10.

Goldfried, M. R., Castonguay, L. G., \& Safran, J. D. (1992). Core issues and future directions in psychotherapy integration. In J. C. Norcross \& M. R. Goldfried (Eds.), Handbook of psychotherapy integration (pp. 593-616). New York: Basic Books.

Goldfried, M. R., \& Newman, C. F. (1992). A history of psychotherapy integration. In J. C. Norcross \& M. R. Goldfried (Eds.), Converging themes in psychotherapy (pp. 3-49). New York: BasicBooks.

Gonçalves, O. (1989). A cognitive-developmental approach to the conceptualization and treatment of agoraphobia. Paper presented at the Counseling Psychology Regional Conference, Los Angeles, CA.

Gonçalves, O. F. (1994). Cognitive narrative psychotherapy: The hermeneutic construction of alternative meanings. Journal of Cognitive Psychotherapy, 8, 105-125.

Gonçalves, O. F. (in press). Hermeneutics, constructivism and cognitive-behavioral therapies: From the object to the project. In R. A. Neimeyer \& M. J. Mahoney (Eds.), Constructivism in psychotherapy. Washington, DC: APA.

Grencavage, L. M., \& Norcross, J. C. (1990). Where are the commonalities among the therapeutic common factors? Professional Psychology: Research and Practice, 40, 247-254.

Guidano, V. S., \& Liotti, G. (1983). Cognitive processes and emotional disorders: A structural approach to psychotherapy. New York: Guilford Press.

Gurman, A. S. (1981). Integrative marital therapy: Toward the development of an interpersonal approach. In S. H. Burman (Ed.), Forms of brief therapy (pp. 59-84). New York: Guilford Press.

Halleck, S. (1971). Therapy is the handmaiden of the status quo. Psychology Today, 4, 30-34, 98-100.

Hartman, A., \& Laird, J. (1983). Family centered social work practice. New York: Free Press.

Held, B. S. (1986). The relationship between individual psychologies and strategic/systemic therapies reconsidered. In D. E. Efron (Ed.), Journeys: Expansion of the strategic-systemic therapies (pp. 222-260). New York: Brunner/Mazel.

Heppner, P. P., \& Claiborn, C. D. (1989). Social influence research in counseling. Journal of Counseling Psychology, 36, 365385.

Hershenson, D. B., Power, P. W., \& Seligman, L. (1989). Mental health counseling theory: Present status and future prospects. Journal of Mental Health Counseling, 11, 44-69.

Herr, E. L. (1991). Challenges to mental health counselors in a dynamic society: Macrostrategies in the profession. Journal of Mental Health Counseling, 13, 6-20.

Hoffman, L. (1990). Constructing realities: An art of lenses. Family Process, 29, 1-12.

Hoffman, L. (1992). A reflexive stance for family therapy. In S. McNamee \& K. J. Gergen (Eds.), Therapy as social construction (pp. 7-24). London: Sage.

Hoshmand, L. T., \& Polkinghorne, D. E. (1992). Redefining the 
science-practice relationship and training. American $P_{\text {sycholo- }}$ gist, 47, 55-66.

Howard, G. (1984). A modest proposal for a revision of strategies of counseling research. Journal of Counseling Psychology, 31, $430-441$.

Ibrahim, F. A. (1985). Effective cross-cultural counseling and psychotherapy: A framework. The Counseling Psychologist, 12, 625-638.

Imber-Black, E. (1988). Families and larger systems: A family therapist's guide through the labyrinth. New York: Guilford Press.

Ivey, A. E. (1986). Developmental therapy: Theory into practice. San Francisco, CA: Jossey-Bass.

Ivey, A. E. (1991). Developmental strategies for helpers: Individual, family, and network interventions. Pacific Grove, CA: Brooks/Cole.

Ivey, A. E., Gonçalves, O. F., \& Ivey, M. B. (1989). Developmental therapy: Theory and practice. In O. Gonçalves (Ed.), Advances in the cognitive therapies: The constructive-developmental approach (pp. 91-110). Porto: APPORT.

Ivey, A. E., \& Ivey, M. B. (1990). Assessing and facilitating children's cognitive-development: Developmental counseling and therapy in a case of child abuse. Journal of Counseling and Development, 68, 299-305.

Ivey, A. E., \& Rigazio-DiGilio, S. A. (1991). Toward a developmental practice of mental health counseling: Strategies for training, practice, and political unity. Journal of Mental Health Counseling, 13, 21-36.

Kabat-Zinn, J. (1990). Full castrophe living. New York: Delta.

Katz, J. (1985). The sociopolitical nature of counseling. The Counseling Psychologist, 13, 615-624.

Kohut, H. (1984). How does analysis cure? Chicago, IL: University of Chicago Press.

Kuhn, T. S. (1970). The structure of scientific revolutions, 2 nd. ed. Chicago: University of Chicago Press.

LaFromboise, T. (1988). American Indian mental health policy. American Psychologist, 43, 388-397.

Lambert, M. J. (1992). Psychotherapy outcome research: Implications for integrative and eclectic therapists. In J. C. Norcross \& M. R. Goldfried (Eds.), Handbook of psychotherapy integration (pp. 94-129). New York: Basic Books.

Lambert, M. J., \& Bergin, A. E. (1992). Achievements and limitations of psychotherapy research. In D. K. Freedhiem (Ed.), History of psychotherapy: A century of change (pp. 360-390). Washington, DC: APA.

Lax, W. D. (1992). Postmodern thinking in clinical practice. In S. McNamee \& K. J. Gergen (Eds.)., Theory as social construction (pp. 69-85). London: Sage.

Lazarus, A. A. (1989). The practice of multimodal therapy. Baltimore, MD: Johns Hopkins University Press.

Levy, C. (1973). The value base of social work. Journal of Education for Social Work, 9, 34-42.

McGoldrick, M., Pearce, J. K., \& Giordano, J. (Eds.). (1982). Ethnicity and family therapy. New York: Guilford Press.

Mahalik, J. R. (1990). Systematic eclectic models. The Counseling Psychologist, 18, 655-679.

Mahoney, M. J., Norcross, J. C., Prochaska, J. O., \& Missar, C. D. (1989). Psychological development of optimal psychotherapy: Converging perspectives among clinical psychologists. Journal of Integrative and Eclectic Psychotherapy, 8, 251-263.
Masterson, J. (1981). The Narcissistic and borderline disorders: An integrated developmental approach. New York: Brunner/Mazel.

Meyers, H., Wohlford, P., Guzman, L., \& Echemendia, R. (Eds.). (1991). Ethnic perspectives on clinical training and services in psychology. Washington, DC: American Psychological Association.

Minuchin, S. (1974). Families and family therapy. Cambridge, MA: Harvard University Press.

Minuchin, S., \& Fishman, H. C. (1981). Family therapy techniques. Cambridge, MA: Harvard University Press.

Nobles, W. (1972). African philosophy. In R. L. Jones (Ed.), Black psychology (pp. 18-32). New York: Harper \& Row.

Norcross, J. C., \& Prochaska, J. O. (1988). A study of eclectic (and integrative) views revisited. Professional Psychology: Research and Practice, 19, 170-174.

Nwachuku, U. T., \& Ivey, A. E. (1991). Culture-specific counseling: An alternative training model. Journal of Counseling and Development, 70, 106-111.

Omer, H., \& Dar, R. (1992). Changing trends in three decades of psychotherapy research: The flight from theory to pragmatics. Journal of Consulting and Clinical Psychology, 60, 88-93.

Ogbonnaya, A. O. (1994). Person as community: An African understanding of the person as an intrapsychic community. Journal of Black Psychology, 20, 75-87.

O'Sullivan, J., \& Quevillon, R. P. (1992). 40 years later: Is the Boulder model still alive? American Psychologist, 47, 67-70.

Parry, A. (1991). A universe of stories. Family Process, 30, 37-54.

Patterson, G. R. (1971). Families: Application of social learning to family life. Champaign, IL: Research Press.

Pedersen, P. B. (1994). Multiculturalism as a fourth force in counseling. Journal of Counseling and Development, 70, entire issue.

Pedersen, P. B., Draguns, J., Lonner, W., \& Trimble, J. (Eds.). (1989). Counseling across cultures. Honolulu, HI: University of Hawaii Press.

Piercy, F., \& Sprenkle, D. (1985). Family therapy theory development: An integrated approach. In F. P. Piercy (Ed.), Family therapy education and supervision (pp. 47-63). New York: Haworth.

Pinsof, W. (1994). An overview of integrative problem-centered therapy: A synthesis of family and individual psychotherapies. Journal of Family Therapy, 16, 103-120.

Polkinghorne, D. E. (1992). Postmodern epistemology of practice. In S. Kvalve (Ed.), Psychology and postmodernism (pp. 146155). London: Sage.

Ponterotto, J. G., \& Casas, J. M. (1991). Handbook of racial/ethnic minority counseling research. Springfield, IL: Charles C. Thomas.

Raimy, V. C. (1950). Training in clinical psychology. New York: Prentice-Hall.

Rice, L. N., \& Greenberg, L. S. (Eds.). (1984). Patterns of change: Intensive analysis of psychotherapy process. New York: Guilford Press.

Rigazio-DiGilio, S. A. (1994). A co-constructive developmental approach to ecosystemic treatment. Journal of Mental Health Counseling, 16, 43-74.

Rigazio-DiGilio, S. A., Gonçalves, O., \& Ivey, A. E. (1994). Developmental counseling and therapy: A model for individual and family treatment. In D. Capuzzi \& D. Gross (Eds.), Coun- 
seling and psychotherapy: Theories and interventions. (pp. 362407). Columbus, OH: Macmillan/Merill.

Rigazio-DiGilio, S. A., \& Ivey, A. E. (1991). Developmental counseling and therapy: A framework for individual and family treatment. Counseling and Human Development, 24(1), 1-20.

Rigazio-DiGilio, S. A., \& Ivey, A. E. (1993). Systemic cognitive developmental therapy: An integrative framework. The Family Journal: Counseling and Therapy for Couples and Families, 1 , 208-219.

Rigazio-DiGilio, S. A., \& Ivey, A. E. (1995). Individual and family issues in intercultural counselling and therapy: A culturallycentered perspective. Canadian Journal of Counselling, 29, 244-261.

Roberto, L. G. (1992). Transgenerational family therapies. New York: Guilford Press.

Sampson, E. E. (1993). Identity politics: Challenges to psychology's understanding. American Psychologist, 48, 1219-1230.

Stiles, W. B., Shapiro, D. A., \& Elliott, R. K. (1986). Are all psychotherapies equivalent? American Psychologist, 41, 165 180.

Sperry, L., \& Carlson, J. (1991). Marriage therapy: Integrating theory and technique. Denver, CO: Love Publishing Company.

Stricker, G., \& Gold, J. R. (Eds.). (1993). Comprehensive handbook of psychotherapy integration. New York: Plenum Press.

Sue, D. W. (1978). Eliminating cultural oppression in counseling: Toward a general theory. Journal of Counseling Psychology, $25,419-428$.

Sue, D. W. (1981). Counseling the culturally different: Theory and practice. New York: Wiley.

Sue, D. W., Ivey, A. E., \& Pedersen, P. D. (1996). A theory of multicultural counseling and therapy. Pacific Grove, CA: Brooks/Cole.

Sue, D. W., \& Sue, S. (1990). Counseling the culturally different. New York: Wiley.

Sugarman, S. (Ed.). (1986). The interface of individual and family therapy. Rockville, MD: Aspen.

Szasz, T. (1961). The myth of mental health. New York: Dell.

Terry, L. L. (1994). The theory behind the theory in DCT and
SCDT: A response to Rigazio-DiGilio. Journal of Mental Health Counseling, 16, 79-84.

Trickett, E., Watts, R., \& Birman, D. (Eds.). (1994). Human diversity: Perspectives on people in context. San Francisco: JosseyBass.

Tyler, J. D., \& Clark, J. A. (1987). Clinical psychologists reflect on the usefulness of various components of graduate training. Professional Psychology: Research and Practice, 18, 381-384.

Vandenberg, B. (1991). Is epistemology enough? An existential consideration of development. American Psychologist, 46, 1278-1286.

Van Hesteren, R., \& Ivey, A. E. (1990a). Counseling and development: Toward a new identity for a profession in transition. Journal of Counseling and Development, 68, 534-536.

Van Hesteren, R., \& Ivey, A. E. (1990b). Integrating counseling and development: Toward a stronger professional identity for counseling psychology. The Australian Counseling Psychologist, 6, 11-26.

Vargas, L., \& Koss-Chioino, J. (Eds.). (1992). Work with culture: Psychotherapeutic interventions with ethnic minority children and adolescents. San Francisco: Jossey-Bass.

Wachtel, E. F., \& Wachtel, P. L. (1986). Family dynamics in individual psychotherapy. New York: Guilford Press.

Watzlawick, P. (Ed.). (1984). The invented reality. New York: Norton.

Wiekel, W., \& Palmo, A. (1989). The evolution and practice of mental health counseling. Journal of Mental Health Counseling, 11, 7-25.

Whitaker, C. A. (1976). The hindrance of theory in clinical work. In P. J. Guerin (Ed.), Family therapy: Theory and practice (pp. 154-164). New York: Gardner Press.

White, M., \& Epstein, D. (1990). Narrative means to therapeutic ends. New York: Norton.

White, J. L., \& Parham, T. A. (1990). The psychology of Blacks: An African-American Perspective, 2nd ed. Englewood Cliffs, NJ: Prentice-Hall.

Winnicott, D. W. (1980). Playing and reality. Canada: Penguin Books. 